\title{
The balance between energy and water preservation in the deposition of dry tailings in wet climates
}

JB Kruyswijk Weir Minerals, The Netherlands

\begin{abstract}
In the past two decades, the mining industry has become more interested in 'dry' tailings. The improved water recovery and potential operational cost benefits have been described by several authors. Compared with conventional tailings disposal, increasing the level of dewatering improves water preservation without having a major impact on operational costs. Dry tailings deposition is a method whereby in the deposition of the tailings, no free water is released. Ultimately, there are two varieties of dry tailings: paste tailings and filtered tailings. Paste tailings are dewatered to the maximum saturated density, whereas filtered tailings are mechanically dewatered to an unsaturated state.

Saturated, loose, contractant tailings are susceptible to liquefaction; the primary mode of failure in most catastrophic tailings storage facility (TSF) failures. Consequently, well-compacted filtered tailings are increasingly considered for risk control. The prerequisite for long-term stability is that the filtered tailings remain unsaturated over time and are in a dense state. This condition may not be met in wet or seasonally wet conditions. When saturation of the tailings may occur, TSF design must make accommodations for sufficient drainage and containment of the stored tailings. Under these conditions, the key differentiator between paste and filtered tailings is the approximate $10 \%$ extra water recovery.

The improved water recovery comes at the expense of a significant increase in power and fuel consumption. In circumstances where the increased spend on the latter two energy sources is offset by the value of the reclaimed water, it may be justifiable to consider the application of filtered tailings. From a sustainability point of view, the increased $\mathrm{CO}_{2}$ emissions will also have to be taken into consideration when selecting the preferred dry tailings deposition method.

In this paper, it is demonstrated that in given applications the balance between energy consumption, water preservation, and $\mathrm{CO}_{2}$ emissions favours paste tailings deposition.
\end{abstract}

Keywords: paste tailings, filters tailings, high-density tailings, tailings management, water preservation, $\mathrm{CO}_{2}$ emissions, power consumption, fuel consumption, sustainability

\section{Introduction}

The global mining industry currently produces approximately 19 billion cubic metres of tailings annually (Baker et al. 2020; www.worldminetailingsfailures.org) and, with the growing demand for metals and minerals, as well as reduced ore grades, this volume is set to continue to rise. In the wake of several catastrophic tailings storage facility (TSF) failures, tailings management has become one of the headline issues for the industry.

Water saturation plays a critical role in TSF stability. Therefore, storing tailings in an unsaturated, dry form is becoming increasingly common. In dry climates or locations where the availability of water is scarce, dry stacking improves water preservation. The stability of compacted dry stacks is well established and has been embraced by regulators and miners globally as an effective method for reducing the risk of catastrophic TSF failure.

The world is facing an existential challenge: climate change. The mining industry has a key role to play with some critical minerals enabling the low-carbon transition required to meet the targets set by the United 
Nations in the Paris Agreement. The electrification of mining equipment and the implementation of more energy efficient processes and equipment will also play a part in meeting these targets.

In an industry in which emissions are high, relatively small improvements can have significant benefits. With regards to tailings, an approach focused on energy, water and footprint preservation must consider the entire process flow - from the start of the dewatering process through to deposition in the TSF. The preferred tailings storage method should prioritize optimized water preservation and sustainable long-term stability at the lowest possible emissions.

\subsection{Dry tailings}

Producing dry tailings is energy intensive. The dewatering, cake handling, spreading, and compaction of dry tailings requires significant amounts of energy, resulting in increased emissions compared with thickened or paste tailings systems. In dry climates, this is partially offset by the absence of the need to construct complex retaining dams. When space is at a premium, or as regulations become more stringent, filtering tailings is a potential solution (Watson et al. 2010).

However, in wetter climates, the precipitation exceeds evaporation and resaturation of the tailings over time cannot be excluded. The benefits in these conditions are limited, if there are any at all.

While, in the short-term, there may appear to be advantages from a stability and safety standpoint, careful design and management are necessary for long-term stability. Dropping filter performance, variability in ore characteristics, and weather conditions may cause the filter cake to retain a level of saturation. Subsequent resaturation can also occur due to infiltration, either from rainfall or springs. Downward migration of moisture - through unsaturated soil moisture transfer mechanisms from upper layers or consolidation of the stack as it grows in height-may cause the lower layer of the stack to become saturated (Javadi et al. 2020).

Irrespective of the working principle, each of these phenomena results in the resaturation of the stored tailings, thereby introducing stability risks to the TSF, if not compacted to a specific threshold density. In these conditions, the uncompacted dry stack must be constructed with identical drainage systems and retaining embankments as hydraulic tailings deposition methods. Several authors have described the importance of understanding tailings characteristics and their implications on TSF design. Ulrich \& Coffin (2013) provide a good overview of the considerations in TSF design for filtered tailings.

Saturated conditions have contributed to all large TSF failures. However, it can also be concluded that such accidents often occur as a result of poor tailings management, including poor water control resulting in low density/contractant tailings. Considering the severe and sometimes irreversible economic, social and environmental consequences of poor tailings management, the need for a considered and careful approach is obvious (Adianshy et al. 2015).

The benefits of high-density tailings storage are known and will become more prominent, particularly as external pressures force mining operators to seek alternative strategies to conventional wet disposal techniques for tailings disposal (Carneiro \& Fourie 2018).

In most cases, the application of dry tailings is predominantly driven by water preservation, footprint reduction, and TSF stability benefits. The objective of this holistic case study is to provide a high-level assessment of the utility costs (water and power) and the feasibility of the additional capital investment required to achieve improved water recovery. Within the bounds of economic viability, there needs to be major investment in achieving the global sustainability goals. With that in mind, what follows is an assessment of the emissions related to the tailings handling flow sheet.

\section{Methodology}

High commodity prices and favourable market forecasts have increased activity in both greenfield and brownfield projects. A medium-sized gold-copper operation with an annual run-of-mine (ROM) production of $2 \mathrm{Mt}$ is considered in this study. 
Two tailings disposal methods are assessed for water preservation, energy consumption and $\mathrm{CO}_{2}$ emissions. Both are 'dry' tailings disposal methods, meaning no bleed water is recoverable from the TSF. The two methods are:

1. Paste tailings.

2. Filtered tailings.

Processing annually $2 \mathrm{Mt} \mathrm{ROM}$ ore generates a tailings mass flow of $240 \mathrm{t}$ dry solids per hour.

\subsection{Tailings process flow}

The tailings handling system can be divided into two components:

1. Tailings dewatering.

2. Transportation and placement.

In the case of paste tailings, the dewatering process makes use of a paste thickener to achieve the desired product. The underflow is then pumped to the TSF using positive displacement (PD) pumping technology, as presented in Figure 1. The flow sheet for the filtered tailings is more complex and comprises a conventional thickener, followed by filtration. Refer to Figure 2 for the process flow of the filtered tailings. For the filtration stage, it is assumed a filter press is used. The tailings characteristics may also require air blowing to reach the target density. This additional step significantly increases the absorbed power for dewatering. The power draw for tailings dewatering is given in Table 1.

The resulting filter cake is transported by trucks to the TSF; it is then spread and compacted at the TSF, which is crucial to ensure stability. Spreading of the tailings is done by means of tracked dozers, while compactors are employed for the consecutive compacting of the tailings.

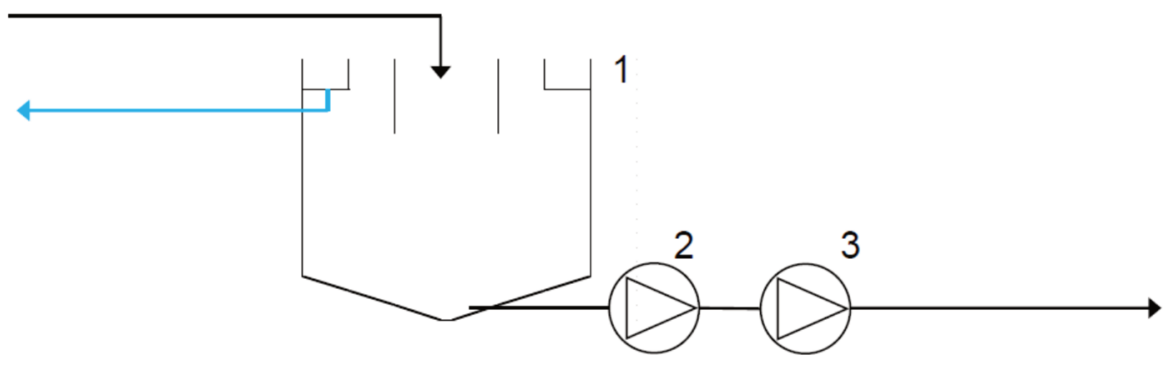

Figure 1 Paste tailings process flow: (1) Thickener; (2) Centrifugal feed pump; (3) PD pump
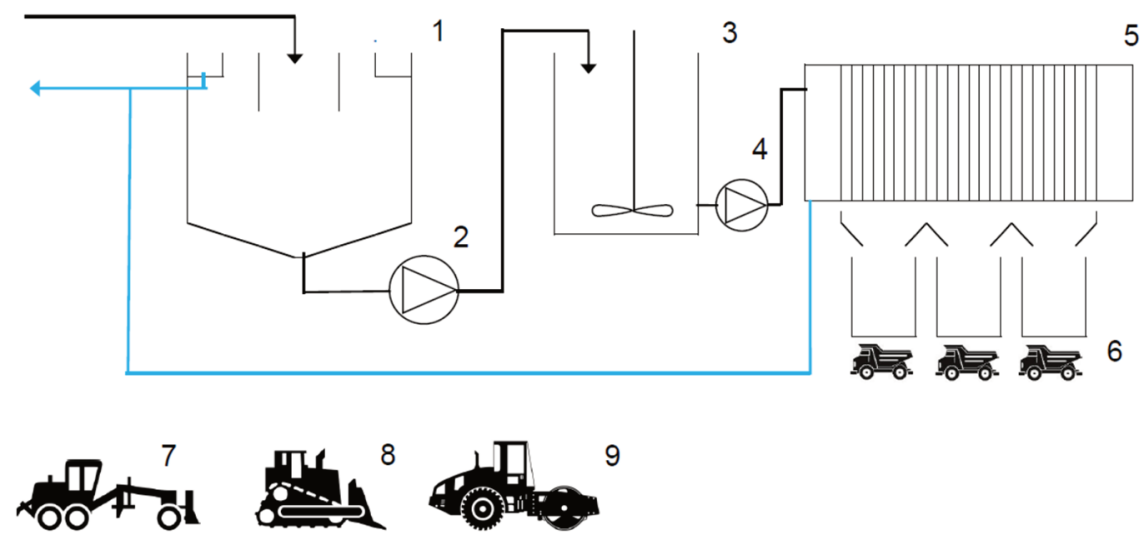

Figure 2 Filtered tailings process flow and required equipment for transportation, spreading and compaction: (1) Thickener; (2) Centrifugal underflow pump; (3) Buffer tank; (4) Filter press feed pump; (5) Filter press; (6) Trucks; (7) Motor grader for haul road maintenance; (8) Dozer for spreading; (9) Compactor 
Table 1 Dewatering energy consumption. Included for paste thickening: feed pump, floc dosing, rake drive. Included for filter press: thickening including feed pump, floc dosing and raking, underflow pumping, agitation of intermediate buffer tank, filter press feed pumps, filter press and cake squeezing. Absorbed power in kWh per dry tonne solids

\begin{tabular}{ll}
\hline Dewatering energy consumption & \\
\hline Paste thickening & $1.0 \mathrm{~kW} / \mathrm{t}$ \\
Filter press, no cake blowing & $2.0 \mathrm{~kW} / \mathrm{t}$ \\
Filter press, with cake blowing & $6.2 \mathrm{~kW} / \mathrm{t}$ \\
\hline
\end{tabular}

\subsection{Tailings storage facility design and location}

For the purposes of this study, the TSF is assumed to be constructed in a ring dyke configuration to a maximum elevation of approximately $40 \mathrm{~m}$. The TSF is located in flat terrain, approximately $1 \mathrm{~km}$ from the processing plant (Figure 3). It is assumed the climatological and geological conditions at the location are wet, or at least such that in the case of dry stacking the change of the tailings saturating over time cannot be excluded. Measures will need to be taken to avoid the tailings from becoming saturated by avoiding water seepage from the surface or to intercept and convey free water that accumulates within the TSF (Ulrich \& Coffin 2013). Design measures consist of retaining embankments, surface drains and runoff diversion systems, drainage systems and zonation in the deposition of the tailings.

Implementing all the required design measures in the TSF to safeguard long-term stability in these conditions reduces the initial cost advantage of the dry stackable filtered tailings. In given conditions, construction costs for long-term containment of filtered and paste tailings may be considered equal. In these circumstances, the costs cancel out and can be disregarded in high-level cost comparisons for the purpose of selecting a preferred high-density tailings handling method.

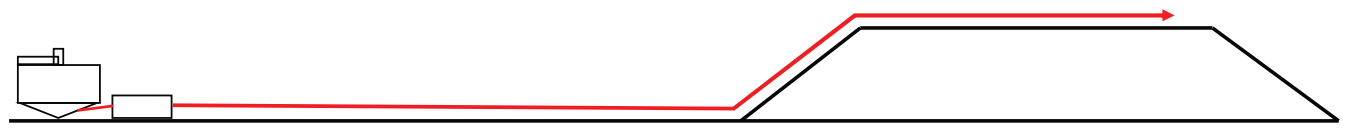

Figure 3 Schematic tailings storage facility (TSF) layout. The TSF is located at $1 \mathrm{~km}$ from the processing plant. The rectangular shaped TSF covers approximately $250,000 \mathrm{~m}^{2}$ and is constructed to a maximum height of $40 \mathrm{~m}$ in four $10 \mathrm{~m}$ raises

\subsection{Water preservation}

Effective water consumption is site specific and requires a case-by-case assessment. For the purposes of this paper, the water preservation calculations consider interstitial losses at the TSF only. Water losses due to seepage and evaporation are not included (Moolman \& Vietti 2012). The contribution of captured runoff water to the overall water balance depends on the location of the TSF and may vary seasonally. For this reason, runoff water is not considered in the water preservation calculations. Operating in a (seasonal) wet climate might have a positive effect on the water preservation through the ability to reclaim the captured runoff water.

The fundamental parameter in the water consumption model is the volumetric flow rate of make-up water required to account for water loss (Möller et al. 2012). When no reservation is made for captured surface runoff, the required make-up water is defined by the difference between the interstitial water entrained in the paste and the filter cake.

Overall water recovery is the ratio of the make-up water to the volume of water reporting to the dilute side of the dewatering process. It is assumed the full plant tailings (FPT) are received in the dewatering circuit at a solids concentration of $25 \%$ by weight. 


\subsection{Energy consumption}

Tailings dewatering, pumping and filter cake handling is energy intensive. While most of the equipment in the paste tailings flow sheet is electrically powered, diesel equipment is still represented. The total absorbed power for the two flowsheets is calculated for electricity and fuel consumption.

Electricity consumption for pumping is calculated from the pumping duty. The electricity consumption for dewatering is estimated at $1.0 \mathrm{kWh}$ per tonne dry solids for paste thickening, $2.0 \mathrm{kWh}$ per tonne dry solids for filtration without cake blow and $6.2 \mathrm{kWh}$ per tonne dry solids for filtration with cake blowing (C Bellot, pers. comm., 2021).

Mobile equipment used for cake haulage, spreading and compacting has been selected from Caterpillar Performance Handbook Edition 35. Fuel consumption is calculated from the handbook assuming moderate operating conditions and applying a load factor of 35\% (Table 2). The working conditions for the graders, dozers and compactors are moderate and fuel consumption is best represented by applying a medium load factor.

Table 2 Average fuel consumption mobile equipment (Caterpillar Inc. 2004)

\begin{tabular}{llll}
\hline Equipment & Load factor & \multicolumn{2}{l}{ Average fuel consumption } \\
\hline Truck & Medium $/ 35 \%$ & 40 & litre $/ \mathrm{h}$ \\
Grader & Medium & 10 & litre $/ \mathrm{h}$ \\
Compactor & Medium & 30 & litre $/ \mathrm{h}$ \\
Dozer & Medium & 30 & litre $/ \mathrm{h}$ \\
\hline
\end{tabular}

\subsection{Utility costs}

The cost of power, water and fuel varies from location to location. Water costs fluctuate from as little as $€ 1.00$ per $\mathrm{m}^{3}$ or less, to more than $€ 4.00$ per $^{3}$. The scarcity of 'clean' water is a global driver of water prices. A water cost of $€ 2.00$ per $\mathrm{m}^{3}$ has been used as the base case (Table 3 ).

Power costs equate to approximately $€ 0.10$ per kWh in most locations.

Fuel prices are affected by taxation and geographical distance from the refinery. Aside from some oil-rich regions, fuel prices are at least $€ 1.00$ per litre or more.

Table 3 Utility unit cost prices

\begin{tabular}{lll}
\hline Water & Euro $/ \mathrm{m}^{3}$ & 2.00 \\
Electricity & Euro/kWh & 0.10 \\
Fuel & Euro/litre & 1.00 \\
\hline
\end{tabular}

\section{6 $\mathrm{CO}_{2}$ emissions}

Burning fossil fuels-whether for electricity generation or to power trucks and other diesel-powered equipment-generates $\mathrm{CO}_{2}$ emissions. Emissions are calculated using an average $\mathrm{CO}_{2}$ emission of $0.46 \mathrm{~kg}$ per kWh absorbed power and $2.657 \mathrm{~kg}$ per litre diesel (Table 4) (Harmeling et al. 2012).

Table $4 \quad \mathrm{CO}_{2}$ emission factors for electricity and diesel fuel

\begin{tabular}{ll}
\hline $\mathrm{CO}_{2}$ emissions & \\
\hline Electricity & $0.46 \mathrm{~kg} / \mathrm{kWh}$ \\
Diesel & $2.657 \mathrm{~kg} / \mathrm{litre}$ \\
\hline
\end{tabular}


The $\mathrm{CO}_{2}$ emissions are calculated for each power source by multiplying the total annual energy consumption by the subsequent emission factor. The sum of the $\mathrm{CO}_{2}$ emissions for electricity and diesel usage represents the annual $\mathrm{CO}_{2}$ emissions for the dewatering, transportation and placement of the tailings.

\section{$3 \quad$ Results}

The input parameters and assumptions are used to model the process flow from dewatering through to tailings deposition for two tailings disposal systems. For these systems, three scenarios are considered: paste tailings deposition, filtered tailings with cake blowing, and filtered tailings without cake blowing.

\subsection{Mass balances}

In this paper, a medium-sized copper-gold mine is considered with a mass throughput of $2 \mathrm{Mt} \mathrm{ROM}$ ore annually. This equates to 240 tonnes of dry solid tailings per hour (Table 5). In the case of the filtered tailings cake, moisture content of the final product is assumed to be similar, hence, the mass balance is not affected. The solids concentration of the filter cake is expressed using the gravimetric definition of solids concentration, which is commonly used in the soil mechanics.

Table 5 Mass balance for the paste tailings option (left) and filtered tailings option (right)

\begin{tabular}{lll}
\hline \multicolumn{3}{l}{ Scenario 1: paste tailings } \\
\hline $\mathrm{S}_{\mathrm{m}}$ & 1,875 & $\mathrm{t} / \mathrm{m}^{3}$ \\
Solids & 240 & $\mathrm{t} / \mathrm{h}$ \\
$\mathrm{C}_{\mathrm{w}}$ & $70 \%$ & $\% \mathrm{w} / \mathrm{w}$ \\
Volume solids & 80 & $\mathrm{~m}^{3}$ \\
Volume mix & 183 & $\mathrm{~m}^{3}$ \\
Volume liquid & 103 & $\mathrm{~m}^{3}$ \\
Yield stress & 150 & $\mathrm{~Pa}$ \\
\hline
\end{tabular}

\begin{tabular}{lll}
\hline \multicolumn{3}{l}{ Scenario 2: filtered tailings } \\
\hline $\mathrm{S}_{\mathrm{m}}$ & $2,308 \mathrm{t} / \mathrm{m}^{3}$ \\
Solids & 240 & $\mathrm{t} / \mathrm{h}$ \\
$\mathrm{C}_{\mathrm{w}}$ unsaturated & 0,85 & $\% \mathrm{w} / \mathrm{w}$ \\
Mass filtercake & 282 & $\mathrm{t} / \mathrm{h}$ \\
Mass water & 42 & $\mathrm{t} / \mathrm{h}$ \\
Mass solids & 240 & $\mathrm{t} / \mathrm{h}$ \\
\hline
\end{tabular}

FPT have been assumed to arrive at the thickener at a solids concentration of approximately $20-25 \%$ and are diluted to facilitate optimal thickener operation. Detailed calculations are not provided in this paper, but equipment sizing and modelling of the flow sheet follows the industry standard methods (Jewell \& Fourie 2006) (Weir pump selection procedures).

\subsection{Equipment selection}

A basic and conceptual equipment sizing and selection has been made. This selection provided the basis for further assessment of the systems water, power and fuel consumption calculations.

In case of the paste tailings, a $30 \mathrm{~m}$ diameter paste thickener with peripheral systems is selected. The paste underflow fed into the PD pump using centrifugal pump. In the case of filtered tailings, the FPT are thickened with a conventional thickener and then filter pressed. The filter cake is trucked over an average distance of $2.5 \mathrm{~km}$ to the TSF using two 40 tonne off-road dump trucks. At the TSF, a tracked dozer spreads the tailings and they are then compacted using a single compactor. If the target density in the filtration step is not achieved, cake blowing is required. This requirement adds significant compressor upgrades to the equipment selection (approximately $1,000 \mathrm{~kW}$ ).

\subsection{Water conservation}

In the paste tailings option, $103 \mathrm{~m}^{3}$ water is contained in the paste and pumped out to the TSF. When the alternative filtered tailings method is deployed, the water losses to the TSF are reduced by $59 \%$ to $42 \mathrm{~m}^{3}$ per 
hour. This reduction in water recovery may look impressive but is put in perspective when the gain in overall water recovery is considered. The overall recovery of water improves $10 \%$ from $86 \%$ for paste tailings to $94 \%$ for filtered tailings (Figure 4).

This saving is considerable but it comes at the expense of significant additional absorbed power for dewatering.

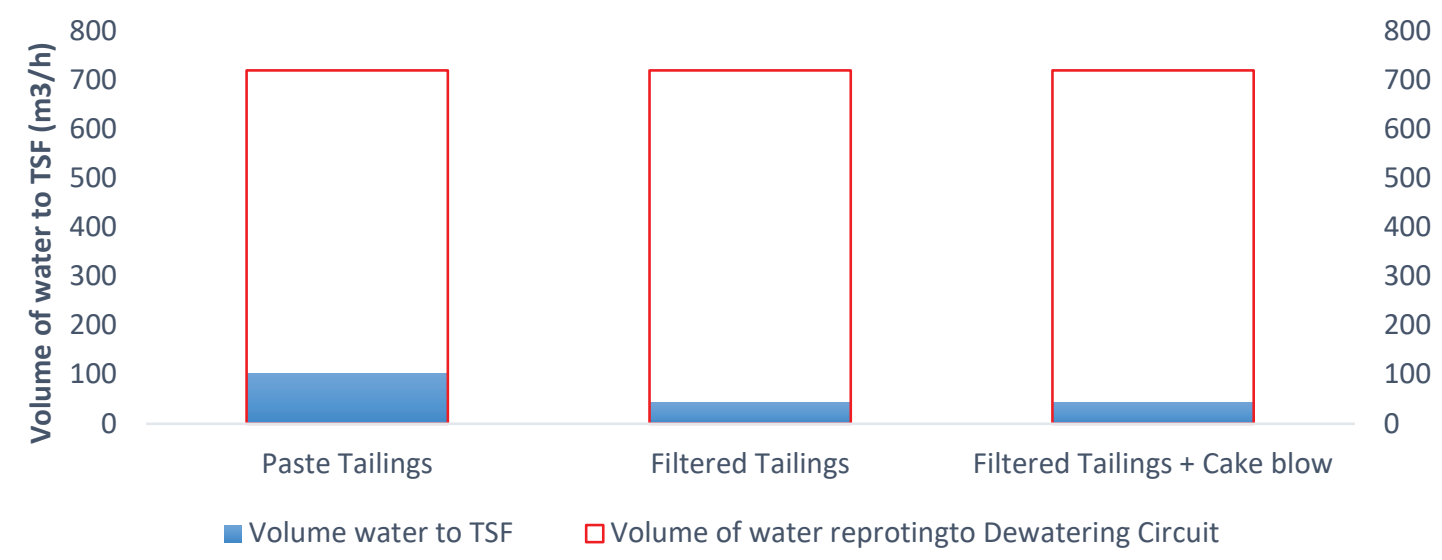

Figure 4 Water preservation. The outline represents the total volume of water reporting to the dewatering circuit for the paste tailings is $86 \%$ versus $94 \%$ for the filtered tailings

\subsection{Absorbed power}

The power usage for the installed equipment has been calculated using the input parameters as stated above. The absorbed power usage is outlined in Table 6 . The figures confirm the general assumption that filtering tailings is energy intensive. In applications where the filter press design or cake blowing is required, energy consumption for the dewatering stage is approximately seven times higher compared with paste.

Based on the data, it can be concluded that, as a rule of thumb, the energy consumption for dewatering triples when changing from paste to filtered tailings. And when cake blowing is required to achieve the target cake moisture content, energy consumption doubles again.

Figure 5 plots the total annual absorbed power for the dewatering and pumping of the tailings. The total absorbed power for the paste and filtered tailings without cake blowing is relatively similar. It is important to note, though, that in the paste tailings scenario transportation of the tailings to the TSF is included, whereas for the filtered tailings the transportation is included in the fuel consumption figures (Table 7).

Table 6 Absorbed power in $\mathbf{k W h}$ per hour

\begin{tabular}{lllll}
\hline Absorbed power & & Paste tailings & Filtered tailings & Filtered + cake blow \\
\hline Pumping & $\mathrm{kWh} / \mathrm{h}$ & 440 & 38 & 38 \\
Thickening & $\mathrm{kWh} / \mathrm{h}$ & 240 & 240 & 240 \\
Filtration & $\mathrm{kWh} / \mathrm{h}$ & - & 480 & 1.488 \\
Total absorbed power & $\mathrm{kWh} / \mathrm{h}$ & 680 & 758 & 1.766 \\
\hline
\end{tabular}




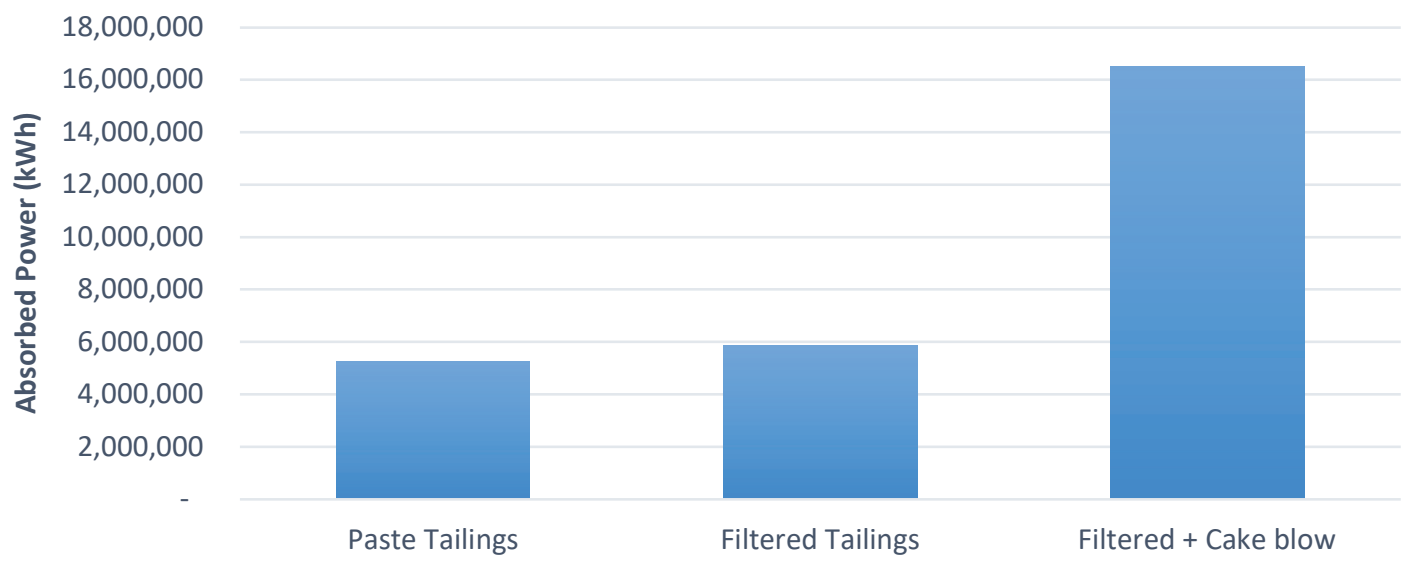

Figure 5 Absorbed power in kWh per annum. Note that in the paste tailings figure, the power absorbed for pumping the tailings to the tailings storage facility is included, whereas for the filtered tailings scenarios, transportation is done by means of trucks

Table 7 Annual fuel consumption in litres

\begin{tabular}{lllll}
\hline Fuel consumption & & Paste tailings & Filtered tailings & Filtered + cake blow \\
\hline Trucking & Litre/annum & - & 823.878 & 823.878 \\
Grading & Litre/annum & - & 62.415 & 62.415 \\
Spreading & Litre/annum & - & 157.680 & 157.680 \\
Compacting & Litre/annum & 157.680 & 157.680 \\
Annual fuel consumption & Litre/annum & - & 1.201 .653 & 1.201 .653 \\
\hline
\end{tabular}

\subsection{Fuel consumption}

A fleet of diesel-powered equipment hauls, spreads and compacts the filtered tailings. The fuel consumption of the fleet adds up to 1.2 million litres per annum. Table 7 shows that trucking the filter cake to the TSF represents $69 \%$ of the total fuel consumption. The spreading and compacting accounts for the remaining $31 \%$. This process is integral to ensuring the stability of the TSF; thus, this cost is not easily reduced.

\subsection{Utility costs}

The cost of make-up water, electricity and fuel represent a significant proportion of the overall operational costs. Other significant contributing expenses include labour, maintenance and spares. The latter two cost components are not further quantified in this paper. Freshwater availability may be limited in some locations, which is reflected in increased water costs. Improving water recovery is, therefore, both an environmental and an economical benefit. There is a global trend towards minimising water use in order to optimise operational costs (Sofrà \& Boger 2002). Moreover, 'dry' tailings are increasingly being considered as a tailings management solution not only for reasons associated with water preservation, but also because they offer benefits with regard to TSF stability.

Figure 6 shows the annual water, power, fuel and total utility costs. When comparing the water costs for paste tailings and filtered tailings, a significant saving can be observed. This saving is offset by an increase in power and fuel costs. Despite an initial saving of $59 \%$ on water expenses, overall utility costs are $15 \%$ higher. Furthermore, when cake blowing is required, utility costs are $66 \%$ higher compared with paste tailings disposal. 


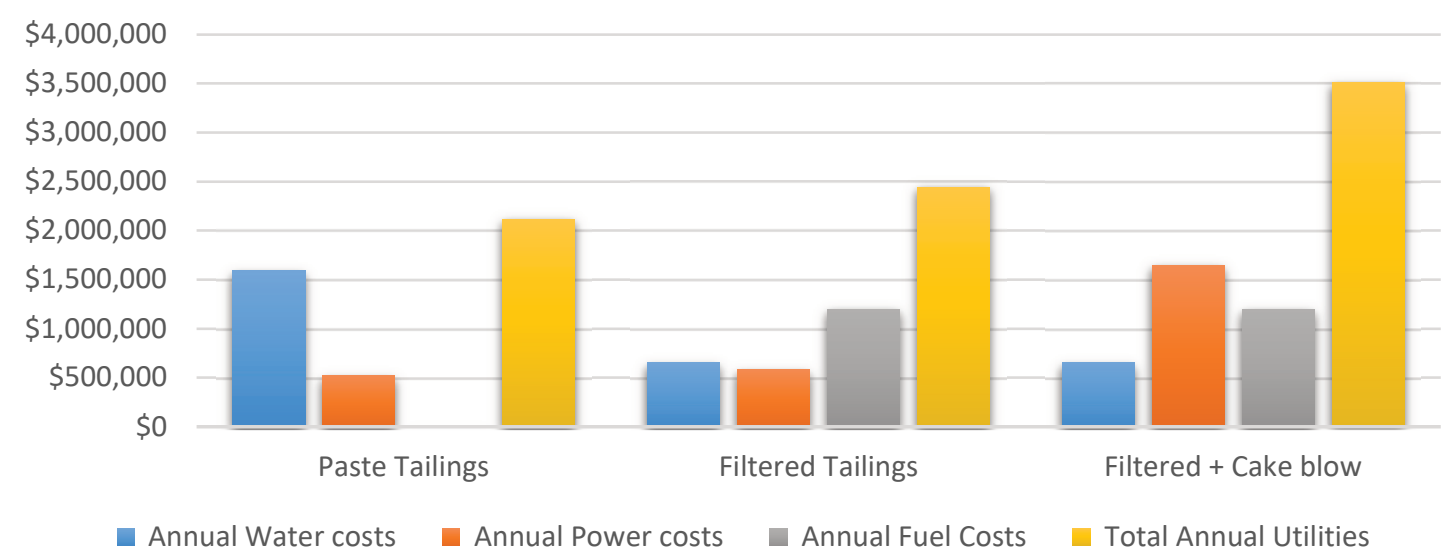

Figure 6 Annual utility costs

\subsection{Economic evaluation}

Comparing the cost benefits of water recovery with the increased cost of energy provides a quick assessment of the viability of the selected method. The proposition is that the net worth of water must at least cover the energy spent for recovery. In wet conditions, the risk of resaturation of the placed tailings, or the formation of saturated zones in the TSF, may occur. To mitigate this risk, design measures will have to be taken (see Section 2.2). Under these conditions, TSF construction costs for paste and filtered tailings cancel each other out and can be disregarded when carrying out high-level cost comparisons.

At a water cost of $€ 2.69$ per $\mathrm{m}^{3}$, the utility costs for paste tailings and filtered tailings are the same. The water costs need to increase to $€ 4.96$ per $\mathrm{m}^{3}$ for the utility costs of the filtered tailings with cake blowing to reach the cost level of paste tailings.

Finding the balance between water and energy costs is only one component in the full-scale comparison of tailings deposition methods. Labour costs and spares and maintenance costs are two additional components in this comparison. A detailed cost of ownership assessment has not been part of the scope of this paper. Costs for the extra approximate 20 FTEs required to operate the filtered system are not considered in the evaluation of the operational costs. Depending on the geographic location of the mine, labour costs can contribute significantly to the operational costs.

The additional capital expenditure required to install a filtered tailings system of the considered size are approximately $€ 15 \mathrm{M}$ for the filters only.

When assuming industry standard criteria for the feasibility assessment of a filtered tailings system, water costs must significantly exceed $€ 7.00$ per $\mathrm{m}^{3}$ to break even.

The trend towards minimising water use and storage as a means of reducing operational costs and increasing the profitability of mine operations, as described by Sofrà \& Boger (2002), has driven the transition from diluted tailings to thickened and paste tailings. Meanwhile, the current trend towards dry tailings is more influenced by environmental and safety considerations.

\subsection{Emissions}

The combustion of fossil fuels to generate electricity or to power mobile equipment releases greenhouse gases into the atmosphere. Reducing these emissions is critical to mitigate the effects of climate change. Selecting methods for tailings disposal, therefore, cannot be exclusively informed by economic factors; consideration should also be given to more energy efficient solutions that help reduce $\mathrm{CO}_{2}$ emissions.

Diesel-powered mobile equipment contributes between $30 \%$ and $54 \%$ of the total emissions depending on filtration efficiency. All diesel emissions are associated with the haulage, spreading and compacting of tailings; truck haulage of tailings, for instance, emits twice the amount of $\mathrm{CO}_{2}$ compared to paste pumping 
$(3,193 \mathrm{t} /$ annum and 1,564 t/annum, respectively). Where the electricity is generated via gas-fired power stations, the diesel emission ratio is higher again.

Figure 7 shows the relative contribution from each required piece of mobile plant in deposition of filtered tailings; spreading and compacting accounts $26 \%$ to the total diesel related emissions.

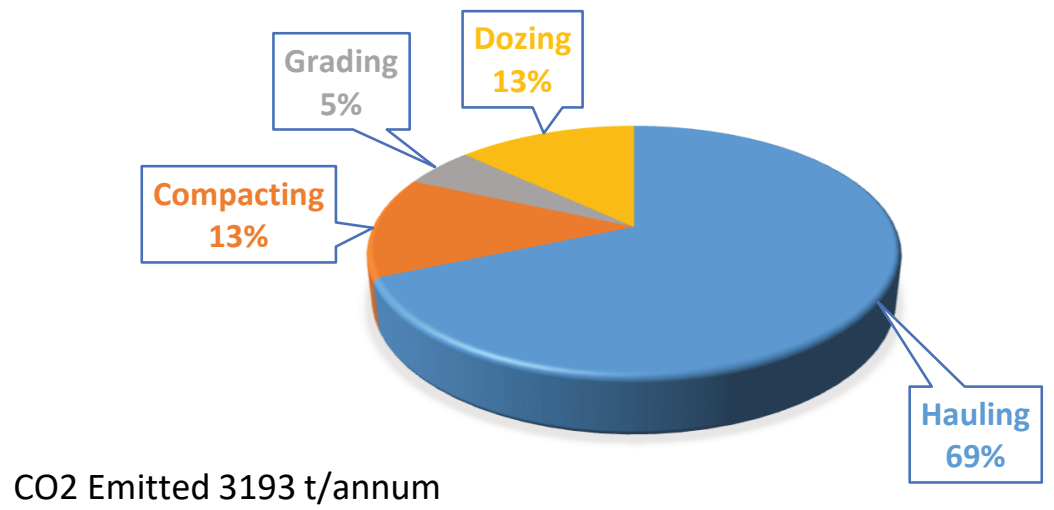

Figure 7 Annual $\mathrm{CO}_{2}$ emissions for the trucking and placement of filtered tailings. Note that $26 \%$ of the emissions result from spreading and compaction of the tailings

The total combined $\mathrm{CO}_{2}$ emissions for paste and filtered tailings are presented in Figure 8 . The filtered tailings disposal, including truck haulage, emits 2.4 times more $\mathrm{CO}_{2}$ compared to paste tailings disposal. If cake blowing is required, then emissions are a further 4.4 times higher.

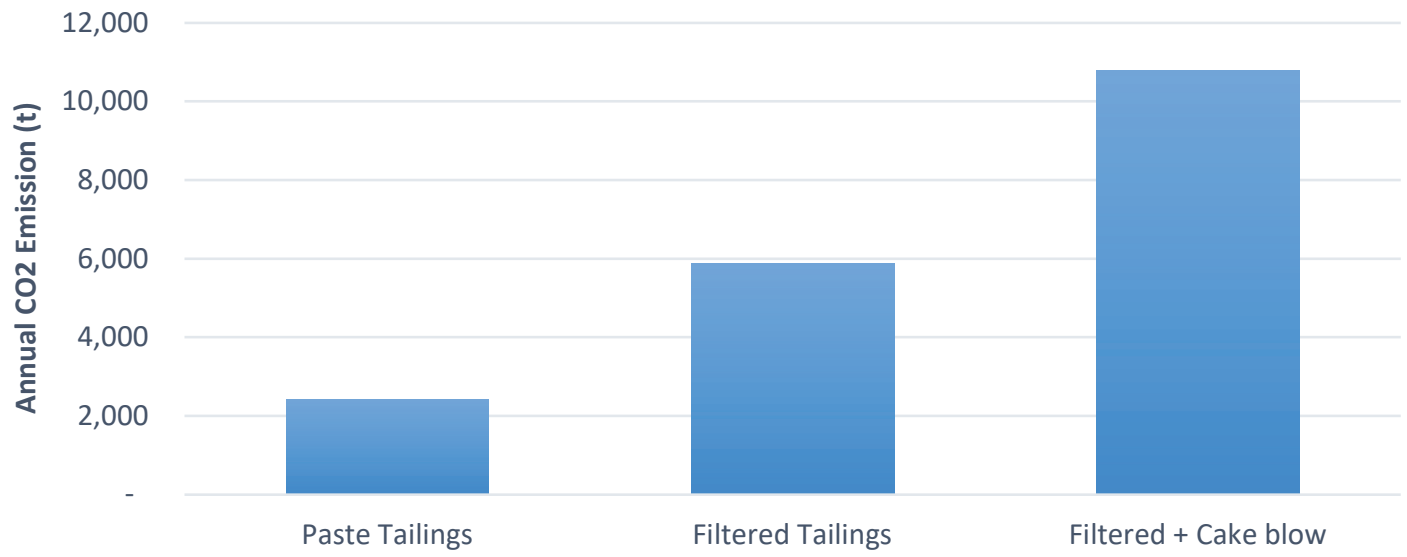

Figure 8 Annual $\mathrm{CO}_{2}$ emissions for paste and filtered tailings handling systems in tonnes per annum. Note that converting from paste tailings to filtered tailings more than doubles the $\mathrm{CO}_{2}$ emissions. When cake blowing is required to achieve target density in the filtration system the emissions double again

\section{Sustainability}

Sustainability is defined as meeting present needs without compromising the needs of future generations. Therefore, sustainable tailings management encompasses the long-term stable storage of tailings, minimising the consumption of valuable resources (water) and limiting the environmental impact by utilising methods and technologies that are both technically and economically feasible.

In Figure 9, the balance between water conservation, $\mathrm{CO}_{2}$ emissions, utility cost and (high-level) capital cost estimates are plotted for filtered and paste tailings. In the comparison, the performance of paste tailings is set at $100 \%$ for all four metrics. A lower score represents an improved performance for the considered metric 
compared to paste tailings. The $10 \%$ improved overall water recovery is offset by significantly lower scores on the cost metrics and more significantly the $\mathrm{CO}_{2}$ emission.

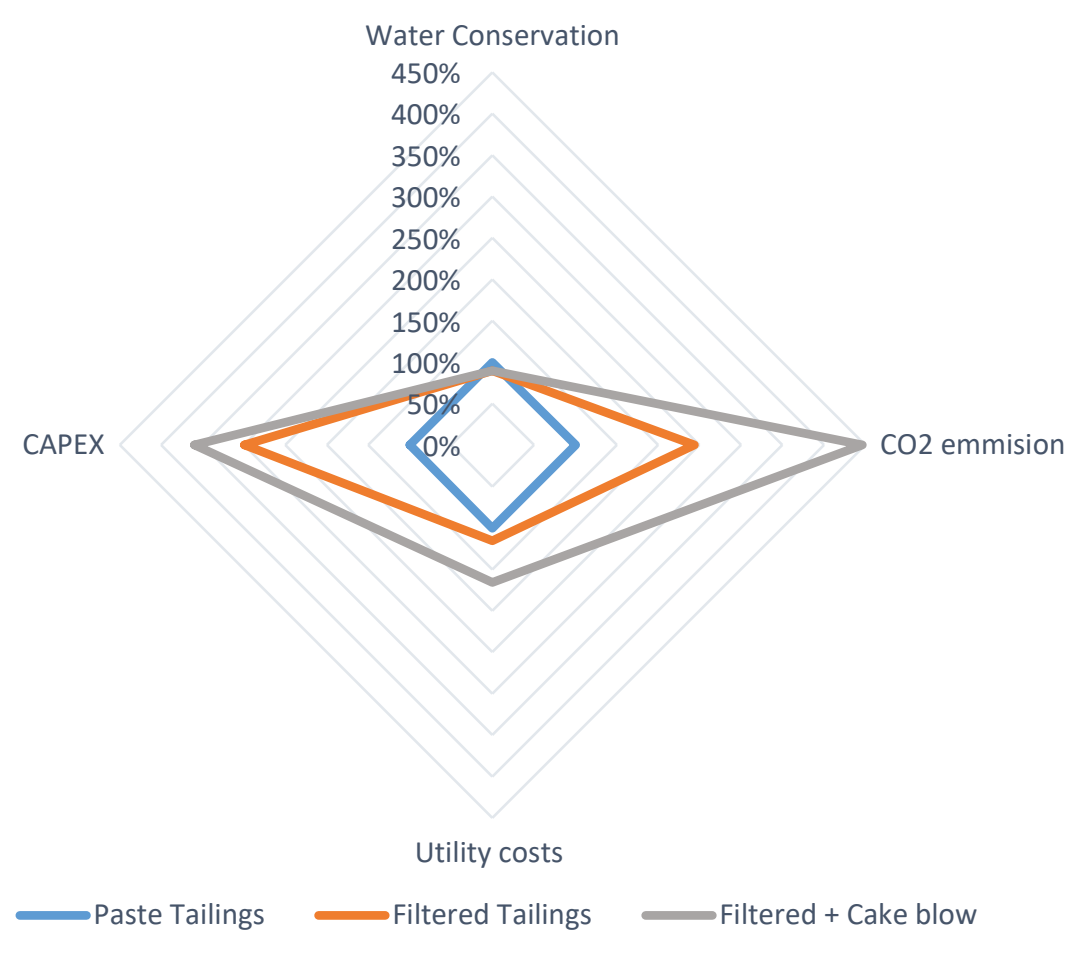

Figure 9 Paste versus filtered tailings, environmental and economic performance comparison

\section{Conclusion}

Dry tailings depositing methods are gaining popularity. This development is driven by the water saving potential and, in the case of filtered tailings, TSF stability. The unsaturated state of the filter cake reduces, if not eliminates, the risk of liquefaction, provided that it is compacted to the threshold of dilatant behaviour.

In arid conditions, the tailings may remain unsaturated permanently, however, in wet or seasonally wet locations, the tailings are at risk of re-saturating over time. Consequently, design measures must be taken to ensure long-term TSF stability. In these circumstances, TSF construction costs for paste and filtered tailings cancel each other out and can be disregarded when carrying out high-level cost comparisons.

The total water recovery is $10 \%$ higher for filtered tailings compared to paste tailings. This efficiency improvement is offset by increased energy consumption for dewatering. According to the data, energy consumption to dewater filtered tailings is, on average, three times higher than for paste. Moreover, when cake blowing is required, content energy consumption doubles again.

Paste tailings offer the most energy efficient dry tailings disposal method, whereas filtered tailings offer the highest water recovery potential. Unit water costs above $€ 2.69$ per cubic metre water balance the increased power costs. When cake blowing is required, the unit cost of water must be in excess of $€ 4.96$ per cubic metre water.

Sustainable tailings deposition needs to be balanced against water preservation, long-term stability, and $\mathrm{CO}_{2}$ emissions. The improved water preservation of filtered tailings comes at the expense of a two to four times increase in $\mathrm{CO}_{2}$ emissions.

Each site will have its own specific tailings storage requirements, and each method has its own applications. However, when the optimum balance between environmental and economic feasibility is holistically assessed, paste tailings are the preferred option. 


\section{References}

Adianshy, JS, Rosano, M \& Keir, G 2015, 'A framework for a sustainable approach to mine tailings management: disposal strategies', Journal of Cleaner Production, vol. 108, part A, pp. 1050-1062.

Baker, E, Davies, M, Fourie, A, Mudd, G \& Thygesen, K 2020, 'Mine tailings facilities: overview and industry trends, in towards zero harm - a compendium of papers for the global tailings review', in B Oberle, D Brereton \& A Mihaylova (eds), Towards Zero Harm: A Compendium of Papers, Global Tailings Review, London, https://globaltailingsreview.org/

Carneiro, A \& Fourie, AB 2018, 'A conceptual cost comparison of alternative tailings disposal strategies in Western Australia', in RJ Jewell \& AB Fourie (eds), Paste 2018: Proceedings of the 21st International Seminar on Paste and Thickened Tailings, Australian Centre for Geomechanics, Perth, pp. 439-454.

Caterpillar Inc. 2004, Caterpillar Performance Handbook Edition 35, Caterpillar Inc., Peoria.

Harmeling, M, Bosselaar, L, Gerdes, J, Boonekamp, P, Segers, R, Pouwelse, H \& Verdonk, M 2012, Berekening van de CO ${ }_{2}-$ Emissies, het Primair Fossiel Energiegebruik en het Rendement van Elektriciteit in Nederland (Calculation of $\mathrm{CO}_{2}$ Emissions, Primary Fossil Energy Consumption and the Efficiency of Electricity in the Netherlands), Department of Economical Affairs, Den Haag.

Javadi, S, Pirouz, B \& Williams, P 2020, Filtered Tailings vs Thickened Tailings - A Holistic View, ATC Williams, http://atcwilliams.com/news/filtered-tailings-vs-thickened-tailings-a-holistic-view

Jewell, RJ \& Fourie, AB (eds) 2006, Paste and Thickened Tailings - A Guide, 2nd edn, Australian Centre for Geomechanics, Perth.

Möller, JHL, Paterson, AJC \& Verbeek, T 2012, 'Thickened tailings - a water and energy consumption perspective', in RJ Jewell, AB Fourie \& A Paterson (eds), Paste 2012: Proceedings of the 15th International Seminar on Paste and Thickened Tailings, Australian Centre for Geomechanics, Perth, pp. 213-224.

Moolman, PL \& Vietti, A 2012, 'Tailings disposal: an approach to optimize water and energy efficiency', Platinum 2012: Proceedings of the Fifth International Platinum Conference: A Catalyst for Change, The Southern African Institute of Mining and Metallurgy Johannesburg, pp. 767-780.

Sofrà, F \& Boger, DV 2002, 'Environmental rheology for waste minimisation in the minerals industry', Chemical Engineering Journal, issue 86, pp. 319-330.

Ulrich, B \& Coffin, J 2013, 'Considerations for tailings facility design and operation using filtered tailings', in RJ Jewell, AB Fourie, J Caldwell \& J Pimenta (eds), Paste 2013: Proceedings of the 16th International Seminar on Paste and Thickened Tailings, Australian Centre for Geomechanics, Perth, pp. 201-221.

Watson, AH, Corser, PG, Garces Pardo, EE, Lopez Christian, TE \& Vandekeybus, J 2010, 'A comparison of alternative tailings disposal methods - the promises and realities', in RJ Jewell \& AB Fourie (eds), Paste 2010: Proceedings of the First International Seminar on the Reduction of Risk in the Management of Tailings and Mine Waste, Australian Centre for Geomechanics, Perth, pp. 499-514. 